\title{
Martínez Andrade, Luis. (2015). Las dudas de Dios. Teología de la liberación, ecología y movimientos sociales. Santander: Otramérica.
}

\author{
Aníbal Pineda Canabal ${ }^{\mathrm{I}}$.
}

Lo propio de Dios es la forma acabada, la majestad, la perfección helada. Desde su grave altura, Dios ordena, da, quita, ora humilla, ora enaltece (Cf. 1 Sam 2,7). ¿Qué le pueden pues importar al que hace "la Osa, el Orión y las Pléyades" (Job 9,9), al omnisciente, las ocupaciones y preocupaciones humanas? Estas no pueden más que resultarle baladíes. Lo que para nosotros es oscuro, se supone que para él es claro como el día. A Él nada se le escapa: lo que somos, lo que fue el mundo, lo que seremos en Él; quién ganará las próximas elecciones, quién el próximo mundial de fútbol, quién el premio Nobel de literatura en 2666, dónde será el próximo atentado terrorista, si hay vida en otro planeta y qué es lo que dice la Piedra de Singapur. Todo lo sabe al punto, al dedillo. Nunca jamás actúa a bote pronto, nunca a ciegas, nunca a la deriva.

Sin embargo, puede y debe existir otra manera de ver a Dios, no ya tanto como ideal hipostasiado - cuyas ardides denunciara Feuerbach - especie de espíritu con quien se puede conversar, sino más bien como entelequia utópica de nosotros mismos, reconciliados con el mundo (Bloch, 2007, p. 413). Frente al Dios "que está como muerto [...que] no es digno de ser implorado, porque no es exigente, ni consuela, ni interviene, ni abate, ni

1 Doctorando del FNRS en la Universidad Católica de Lovaina. Miembro del Grupo de Investigación Humanitas, Universidad Católica de Oriente.

Correo electrónico:anibalpinedac71@gmail.com 
levanta" (Metz, 2002, p. 101), los pobres de América - como tantos otros pobres de tantos otros lados -, a partir de una interpretación existencial crítica de su propia realidad, han sabido inventarse un Padre cercano, compañero de camino de su praxis liberadora.

Pero junto a este amasijo de deseos, de luchas, de resistencias diversas, vino en tanto que momento segundo y como a barlovento de las contradicciones mismas de una época, una reflexión teológica y filosófica cuya naturaleza aparece acaso por primera vez en el universo de la ciencia reciente, como claramente latinoamericana. La teología de la liberación, la ecología, los movimientos sociales están pues a la base de una reflexión original que ha inspirado una bibliografía hoy por hoy abundante. En esta senda se inscribe el último libro de Luis Martínez Andrade publicado por Otramérica.

En la página 216 del texto, que es cuando se termina la lectura, no faltará alguno que tras cerrar el libro y observar la solapa, piense en algún tipo de recurso stendhaliano que justifique la elección del nombre. Como en $L a$ cartuja de Parma, el lugar de la muerte del protagonista, sin relación alguna con el resto del libro, decide el título de la novela. Con el libro de Martínez Andrade parece que hubiese ocurrido lo mismo: tras el punto final, en la última página, se decide casi aleatoriamente el nombre sonoro de su obra.

Así pues, el lector recorre las páginas de Las dudas de Dios - el lector sabe bien que es un libro de entrevistas -, ansiando que dicho título le venga explicado en alguna de las dos introducciones. Y avanza con esta hambre hacia el cuerpo del libro y espera que en alguna conversación, alguno de los entrevistados - representantes todos de lo que podríamos considerar una teoría crítica que discurre en velocidades distintas, en escenarios distintos del planeta, África, Europa o Latinoamérica - pronuncie la enigmática frase.

Las dudas de Dios. El título tintinea, ya no en la inteligencia, se diría en el alma. Siempre se ha visto, en efecto, que "todos parten de que la divinidad es en sí misma un silencio eterno", como escribe el Schelling (2002) de Las edades del mundo, "absorbido por completo en sí mismo [...] esencialmente una voluntad en reposo" (pp. 519, 521). Aquí en cambio, el Dios terrible de que hablábamos al principio, toma forma humana y se hace pasible del humano sentimiento de la duda. Esto no ya en el sentido en que nosotros 
dudemos de él sino en que Él es quien duda ya de sí mismo y en esa duda, abre una posibilidad nueva de relacionarnos con Él.

Se abre el libro con una introducción del colombiano Jesús Alfonso Flórez titulada La minga del pensamiento. Título a la vez hermoso e imposible. Hermoso, porque en efecto, lo que Martínez hace a lo largo del libro es confrontar al lector con una serie de autores de distinta laya: teólogos, filósofos, sociólogos, literatos, todos comprometidos en la construcción de un pensamiento [ea, que comience la feria de neologismos] contrahegemónico, que dé al traste con las aspiraciones universal-totalizantes - universaltotalitarias, las más de las veces - del pensamiento del centro y sus viejos lastres imperialistas y heteropatriarcales. Pero la minga del pensamiento, porque nace de la lucha "anti-estatal, anti-imperialista y anticapitalista" (Martínez, 2015, p. 15) solo puede ser experiencia segunda. Por eso, decimos, es un título imposible. Necesita el apellido "del pensamiento" porque la verdadera minga, aquella que camina - así, transitivamente - palabra y lucha, está expresándose en su cabildo abierto, en un lenguaje bastante más simple con acciones que van más allá de un libro: es la minga que abre caminos en los Andes, que se opone a los designios de las multinacionales, que exige garantías para quienes cultivan la tierra o que juzga al infractor sirviéndose para ello de sus palabreros. Esa minga, sin embargo, inspira el trabajo intelectual de muchos, que de repente se sienten solidarios con su propio pueblo.

Lo que intuye bien el profesor Flórez es la importancia de la teología de la liberación en el libro. Defiende con razón la vigencia de esta teología nuestra contra aquellos que insisten en negarla o en considerarla un fenómeno del pasado. Coincide del todo el autor colombiano con nuestra idea, expresada arriba, según la cual la teología de la liberación se estructura en torno a dos momentos, el de la praxis primera y el de la reflexión de fe sobre dicha praxis. Reconoce la importancia de la mediación socio-analítica en la forma como esta teología se acerca a los problemas de la fe y de la realidad o de la fe en la realidad - como fe sita en una realidad y como fe en que esa realidad es susceptible de cambio -. Hace bien el profesor colombiano en insistir en la importancia de esta reflexión teológica como verdadera escuela de pensamiento crítico que sobrepasa las fronteras de su propia reflexión y es capaz de influir en otros escenarios de la ciencia y el pensamiento como el la corriente decolonial, por ejemplo. 
Discrepamos sin embargo de la fórmula poco afortunada con la que el autor describe el fundamento de la teología de la liberación que según él no es ya "el discurrir academicista, [...ni] el edificio dogmático y del magisterio perse, sino que su fundamento son los diversos sectores populares" (Martínez, 2015, p. 15). Sin excluir que acaso sea nuestra comprensión errada del término "fundamento" el origen de nuestra incomodidad, es posible que la frase confunda el fundamento del quehacer teológico con el punto desde el cual este se ejerce. El fundamento de la teología, también de aquella que se apellida "de la liberación", sigue siendo la Revelación; el locus, en cambio, de esta teología es el pobre, donde la Revelación se revela, como se revela también, por supuesto, en las Escrituras y en la Tradición viva de la Iglesia. En palabras del padre Clodovis Boff (1990), acaso más precisas:

En la raíz última de la teología de la liberación está, temática u operativamente, la fe objetiva (o positiva), esto es, la palabra de Dios o la revelación. Esto es lo que la convierte en «teología». Pero eso no es todo; a continuación, estructural y dialécticamente ligada a la óptica de la fe objetiva, viene la óptica del oprimido, o sea, la fe subjetiva. Esto es lo que la convierte precisamente en teología «de la liberación» (p. 81).

Casi que contradiciendo el punto de vista de Flórez, aparece a continuación la segunda introducción, a cargo de Luis Martínez, bajo el título Instruirnos, conmovernos, organizarnos... Si los puntos suspensivos muestran bien la tensión permanente de la lucha que se expresa de diversos modos y está llamada a reinventarse permanentemente, no creemos, sin embargo, que la instrucción, como lo hemos dicho, sea el primer movimiento. "In the beginning is the scream", nos ha recordado Holloway (2005, p. 1). Por eso, nos parece que solo la indignación ética, como experiencia fundamental nacida de una pasión por la realidad, como dice Casaldáliga (1992, pp. 50ss), puede ser la verdadera catalizadora de toda reflexión que se pretenda liberadora y no lo contrario. La secuencia de los tres verbos pronominales que le sirven pues a Martínez de título para su nota, no deben ser entendidos como una sucesión de momentos cuyo prius temporal lo tendría la instrucción sobre la indignación sino que más bien - y con seguridad el autor concuerda con nosotros en esto- los tres momentos hacen parte de un solo impulso, especialmente en el intelectual que abandona ciertas veleidades propias de su quehacer, entendido de forma burguesa y renuncia al juego de fungir como filósofo del proletariado. 
En una prosa sincera, Martínez habla de su generación como de una que no reconoce en la caída de la Unión Soviética un trauma histórico fundamental. Él es producto de esa generación que vio cómo se apalancaba dondequiera un capitalismo mundialista cuyas ínfulas de eternidad terminaron por parecernos insoportables. Las primeras fallas de ese edificio que parecía establecido para siempre, empezaron a verse pronto. Las luchas de los de abajo pronto mostraron que el gigante tenía pies de barro. Las resistencias, viejas de siglos, siguieron su marcha a pesar del discurso hegemónico que les asignaba una edad pretérita, ida ya para siempre. El Movimiento de los Sin Tierra, los levantamientos indígenas en torno a la celebración del V Centenario del «Descubrimiento», el levantamiento del Ejército Zapatista de Liberación Nacional y tantas otras fuerzas en lucha no permitieron que la herencia de la primera época del boom muriera con los años. Resurgió más bien con fuerza una pléyade de pensadores en un flanco nuevo y potente: el de los estudios poscoloniales, feministas, ecologistas, signos todos que para Martínez representan la vitalidad teórica de América Latina. De esta efervescencia intelectual latinoamericana post-boom dan cuenta, por ejemplo, "la teoría de la dependencia, la investigación acción participativa, la pedagogía de la liberación, la teología de la liberación, la filosofía de la liberación, la psicología social de la liberación, el pensamiento decolonial y la propuesta del Buen Vivir" (Martínez, 2015, p. 16).

De esta epopeya del saber y la lucha - o mejor dicho, al revés: de la lucha y el saber -, la obra que el propio Martínez viene construyendo desde hace varios años a través de sus estudios en México y Europa, es tributaria al tiempo que contribuidora. Las dudas de Dios es en este sentido un testimonio privilegiado la labor de su autor como investigador en sociología. De hecho, las entrevistas que incluye el libro se dieron en el marco de su investigación doctoral sobre el lugar de la ecología en la teología de la liberación y especialmente en la obra de Leonardo Boff, por cierto, de publicación reciente (Martínez, 2016). Si las entrevistas inicialmente recogen parte del trabajo de campo que Martínez inició en París, en 2007, bajo la dirección de Michael Löwy, al mismo tiempo, también logran convertirlo en testigo atento de una época de la historia latinoamericana, cual es, la de los gobiernos progresistas a cuyo fin, a veces dramático, estamos asistiendo.

Pero lo anterior no impide que sea el propio Martínez quien reconozca las falencias y limitaciones de su trabajo: la ausencia de voces femeninas 
que podrían haber ampliado las miras de su texto o su propia condición de sociólogo no-creyente, scriba doctus que trata a veces temas de teología. La anterior condición, más su natural "ausencia de complejos coloniales ni miedo" - como aparece escrito en la solapa del libro - se hallan quizá al origen de ciertas expresiones desconcertantes o aun ingenuas para el lector religioso o teólogo ${ }^{2}$. Vistas, sin embargo, las cosas de otro modo, estas falencias aparentes del texto, se convierten al final en su fuerza puesto que dan cuenta de la capacidad de proyección de la teología de la liberación como esfuerzo de elaboración de una teoría crítica de la sociedad desde el punto de vista de la creencia más allá de sus propios límites, esto es, allende las facultades de teología o los salones de reunión de las parroquias de barrio.

La entrevista con Leonardo Boff, abre el libro y data de 2009. Su importancia radica en que Boff será el hilo conductor que une la mayor parte de las otras entrevistas publicadas. El tema principal y casi exclusivo de la conversación es el motivo ecológico en el pensamiento del teólogo brasileño. En su conversación con Martínez, Boff intenta mostrar las relaciones profundas que existen entre hombre, mundo, materia y Dios para desde allí postular, en línea directa con su tradición franciscana, una nueva mística que integre la vida natural y el imperativo moral del cuidado de la Tierra como casa común. El otro camino de integración de estas tres realidades es político y lleva para él el nombre de ecosocialismo, única alternativa posible al capitalismo que depreda los recursos y pone en peligro incluso la supervivencia de la especie humana. Pero dicho ecosocialismo por el que lucha Boff, debe ir más allá de la narrativa clásica de la lucha de clases, por ejemplo, para "asimilar su base biológica" (Martínez, 2015, p. 35). Así las cosas, se trata no solo de un proyecto económico-político sino además de una propuesta ética en la que todo organismo viviente forma parte de una gran comunidad de vida, concepto en cierta manera superior al de medio ambiente, aunque las razones de esta idea no aparezcan claramente explicitadas.

2 V.g. cuando Martínez dice que Clodovis Boff abandonó la teología de la liberación para abrazar la teología de los obispos de Aparecida (p. 44) como si se tratara de dos campos epistémicos diferentes y opuestos o cuando dice que la "mística" (palabra que pone entre comillas) al interior del MST "no es concebida como distracción metafísica o idealista" (p. 15), afirmación que merecería ser matizada para evitar caer en el radicalismo que opone como irreconciliables contemplación y acción; o peor aún, en un pesimismo de la mística como quietismo, discusión que parece hoy superada en muchos aspectos. 
Resultaría difícil resumir las discusiones de diverso tenor que se dan en cada una de las dieciséis entrevistas que incluye. Estas no vienen presentadas diacrónicamente sino con arreglo a un criterio editorial que no resulta para nada claro. La mayoría de los entrevistados es de nacionalidad brasileńa, pero alcanzan a aparecer otros nombres notables de otras latitudes. Como no se trata aquí de dar cuenta de modo pormenorizado de las ideas centrales de cada diálogo, podemos resumir las entrevistas en el orden en que aparecen así:

1. La entrevista con Jung Mo Sung teólogo brasileño, profesor de la Universidad Metodista de São Paulo: se intenta en un primer momento precisar la importancia de la obra de Leonardo Boff en el contexto histórico cultural latinoamericano para luego centrarse en la importancia de la ecología al interior de dicha obra. El profesor brasileño critica algunos aspectos acaso demasiado teleologistas del pensamiento de Boff, para el que pareciera que el triunfo absoluto del bien está de antemano garantizado. Sin llegar al sofisma reaccionario que pretende de que ni las hojas de los árboles se mueven sin la intervención divina, Boff sí incurriría para él en una suerte de teísmo progresista según el cual, a pesar de las sombras del pasado y el presente, el futuro se revela promisorio, de acuerdo con la promesa divina. Asimismo, Boff incurre para Sung en relativas contradicciones al hablar tanto de antropocentrismo como de capital-centrismo, dos nociones que se excluyen entre sí, a menos que se reconozca entre ellas una relación de tipo causal en donde el capital-centrismo sería extensión y consecuencia lógica del antropocentrismo. Para Boff, la idea del hombre como eje de la realidad y el cosmos estaría al origen del malestar profundo de las sociedades modernas. Sin embargo, es difícil sostener que el ser humano esté en el centro cuando las grandes masas de la población mundial se hallan zaheridas en su dignidad por una economía que los excluye del bienestar al que solo unos cuantos parecen tener derecho. El antropocentrismo como marco conceptual de las filosofías del centro, sería una tara de la cual la obra de Boff no logra deshacerse del todo por más que conozca las tesis de autores como Franz Hinkelammert sobre el capital-centrismo. Para Sung, la idea de futuro optimista que adivina en Boff le resulta antipática pues paraliza las fuerzas de la contestación y la necesidad de la lucha.

2. Una breve entrevista a Frei Betto: aquí el tema preponderante, más allá de lo ecológico en Boff, será el desfase temporal de las izquierdas latinoamericanas, es decir, el hecho de que ciertas reflexiones lleguen, por lo general, tarde a la agenda progresista del subcontinente. En el caso de 
la ecología o de una nueva comprensión de las relaciones de género, la evidencia salta a los ojos.

3. La entrevista al jesuita brasileño João Batista Libanio: tras describir a grandes rasgos la forma en que puede entenderse el franciscanismo natural de la obra de Leonardo Boff, el padre Libanio pasa revista a la situación de los movimientos sociales del Brasil actual. Temas como el Movimiento de los Sin Tierra, la pastoral ecológica, la ecología en general o incluso el relativo eclipse de la teología de la liberación en la agenda eclesial actual son comentados.

4. La conversación con Paulo Nogueira Baptista, profesor en Minas Gerais: el tema preponderante resulta ser el giro ecológico en el pensamiento de Boff, que se produce hacia finales de los años ochenta y los diferentes matices que este adquiere en la obra del brasileño, así como las diferentes críticas que otros autores le han hecho.

5. La entrevista a Enrique Dussel: aquí cambia el tono del libro. La preocupación deja de ser Leonardo Boff y se orienta más bien a las posibilidades de una comprensión crítica de la realidad latinoamericana desde la perspectiva de una filosofía de la liberación. Son temas tratados en la entrevista: el rol del Estado en la teoría política marxista y el redescubrimiento de San Pablo en la filosofía política contemporánea. Dussel abandona la vieja utopía de la muerte del Estado, al que reconoce como necesario, aunque admitiendo al mismo tiempo la necesidad de transformarlo por medio de una nueva concepción de la economía. Vuelve además a aparecer el tema del antropocentrismo. Dussel retoma la consabida crítica a Boff según la cual el problema no es el antropocentrismo, que no existe, sino el capitalcentrismo, que pone el interés económico como valor superior que se pone por encima de la vida humana. Dussel reivindica, sin embargo, el paradigma antropocéntrico desde la idea del hombre como conciencia o autoconciencia de la naturaleza. Pero la oralidad le juega al filósofo argentino malas pasadas en la segunda parte de su charla con Martínez. Su exposición por un lado, en un no advertido lapsus linguae, falsea la parábola del Buen Samaritano y por otro desconcierta con la oscura afirmación según la cual el catolicismo es una invención moderna cuya acta de nacimiento podríamos fijar en el Concilio de Trento. Lo verdaderamente problemático viene cuando Dussel afirma: "el catolicismo nace al mismo tiempo que el Constantismo (sic)" 
(Martínez, 2015, p. 94). Se trata de una afirmación fuerte, seguramente bien fundamentada en la mente de quien la pronuncia, pero lanzada al desgaire, sin que el lector sea advertido acerca de lo que el entrevistado entiende por constantismo. ¿Simple lapsus calami por constantinismo, tal vez? ¿En cuál de sus polisémicos sentidos dicho constantinismo podría ser llamado moderno?

6. La entrevista al novelista y ensayista senegalés Boubacar Boris Diop: pretende ser una reflexión acerca del papel de la literatura y del intelectual en el contexto africano. Esta entrevista si bien logra cambiar el lugar geográfico principal del libro - o sea, América Latina - no invierte para nada el lugar verdadero de la reflexión que son los pueblos del Sur, hermanados por una historia de despojo y de lucha por su liberación. En una especie de invitación a un fail better ${ }^{3}$, Diop desenmascara la falacia reaccionaria que pretende hacernos lamentar las independencias de los estados africanos o aun americanos - por el simple hecho de que las burguesías nacionales hayan acabado siendo, a la postre, en muchos casos, peores que la misma administración colonial.

7. El diálogo con Gilmar Mauro: al dirigente nacional del Movimiento dos Trabalhadores Rurais sem Terra de Brasil se le pregunta acerca de la influencia de la obra de Leonardo Boff en su acción política y cómo el tema ecológico es abordado desde la perspectiva de su organización.

8. La entrevista a Lauri Emilio Wirth: voz protestante por excelencia del libro, el diálogo con este pastor luterano, además de volver sobre el tema del Medio Ambiente, intenta elaborar un diagnóstico de la situación actual de la teología de la liberación. ¿Se trata de algo ya superado? ¿Pertenece a otro tiempo? Como reelaboración de una teoría de la historia, como reivindicación de la dimensión utópica del Reino en tanto que crítica social o como apertura a otras formas de espiritualidad, la teología de la liberación sigue produciendo frutos y abriendo nuevos campos de reflexión.

3 Fallar mejor. Nos referimos, claro, al conocido eslogan de Samuel Beckett ("Worstward Ho" en Dramatic Words and Dialogues, Beckett Short $N^{\circ}$ 2, Londres, John Calder, 1999, p. 7). 
9. Conversación con Michaël Löwy: el autor francobrasileńo subraya la importancia de la apropiación que la teología de la liberación hace del marxismo y la forma como este ha sido entendido desde América Latina. Es resaltado el anticapitalismo católico que contrasta con la ética capitalista, protestante de pleno derecho. Dicho anticapitalismo se expresa no solo en la acción social de muchas comunidades eclesiales de base y en el catolicismo progresista en general sino que aparece con fuerza incluso en las facciones más reaccionarias de la Iglesia, con todo y su nostalgia de sotanas y latines.

10. La entrevista al sociólogo Pedro de Assis Ribeiro de Oliveira: un diálogo-tipo que incluye los temas recurrentes del libro entero, a saber, la obra de Boff, la cuestión ecológica, el antropocentrismo cristiano, las comunidades eclesiales de base, la actualidad de la teología de la liberación; todo desde la perspectiva de este gran conocedor del catolicismo brasileño.

11. El diálogo con Padre Ton: aporta al libro la perspectiva de la izquierda en el poder (Mariton Benedito de Holanda, tras haber dejado el ministerio presbiteral, era a la sazón diputado por el Partido dos Trabalhadores). Qué papel han tenido el catolicismo y la teología de la liberación en el triunfo de Lula o cuáles luchas persisten en la nueva situación del Brasil progresista hacen parte de los temas tratados.

12. Antonio Carmona Báez: en la conversación con el sociólogo puertorriqueño el núcleo temático se desplaza hacia el pensamiento decolonial. Cuba se vuelve objeto de análisis así como las distintas tendencias de la izquierda latinoamericana que lograron por primera vez hacerse al poder, en varios países del subcontinente, al despuntar el alba del nuevo milenio.

13. Gianni Vattimo: una pregunta por la noción que de Dios tiene el autor italiano, da pie para una rica exposición teológica y para la exposición de lo que sería su filosofía de la religión y su concepción de la historia. Resulta interesante la asociación que se hace entre catolicismo y pensamiento débil. La fe católica con toda su carga de dogmas inamovibles, entra no dentro del pensamiento de las lógicas inflexibles y unívocas sino más bien dentro de la conocida idea de pensiero debole. La recepción de Vattimo en Latinoamérica es también ampliamente comentada. 
14. Ramón Grosfoguel: es, con la de Boff y Dussel, una de las entrevistas más largas. Se analiza la importancia de la teología de la liberación en el desarrollo de los estudios decoloniales. Nos parece, sin embargo, que el conocido profesor puertorriqueño lanza alegremente acusaciones fuertes que no se toma el tiempo de probar. Por ejemplo, afirmar que "en el cristianismo originario no existía la idea trinitaria ni [...] el dualismo del mundo espiritual y del mundo material" (Martínez, 2015, p. 186). Creemos que una afirmación de ese tipo es más del orden de la historia de los dogmas y montar sobre ella cualquier afirmación es cuando menos peligroso. Peca además Grosfoguel a nuestro juicio al poner al mismo nivel la Pacha Mama de nuestros pueblos originarios con el Alá del Islam. Tanto la una como el otro son, para él, irreductibles a la idea occidental y cristiano-céntrica de Dios. Grosfoguel parece olvidar, empero, el hecho de que los primeros que asociaron la fe teocréntrica musulmana con la noción griega de Dios no fueron los occidentales tras haber leído el Corán sino los mismos filósofos y la misma tradición clásica musulmana, con sus eminentes cabezas, Avicena o Averroes. Es ingenuo pensar que puesto que Alá jamás se hizo ni se hará hombre entonces es lo mismo que la Pacha Mama, esto es, "una fuerza o energía de vida cósmica” (Martínez, 2015, p. 187). El ser divino del Corán con inteligencia y voluntad no nos parece tan radicalmente diferente del Dios del judeo-cristianismo. La genialidad de Grosfoguel, en cambio, consiste en dar al traste con el tema central del libro: la pregunta por la naturaleza. Esta es, a pesar de todas sus buenas intenciones, eminentemente eurocéntrica. En otras cosmovisiones no existe lo natural a lo que se superponga lo humano, sino más bien un solo cosmos unitario do se vive y respira. La entrevista es además una especie de ajuste de cuentas sumario del profesor caribeño con otros pensadores de la corriente decolonial y especialmente con Walter Mignolo.

15. Raúl Vera: la breve entrevista con el obispo mexicano cierra el libro y sirve como una especie de promesa. Vera, que conoce como pocos la situación de Chiapas y siguió de cerca la insurrección zapatista, además de analizar la situación actual de su país, se muestra animado por la certeza de que la teología de la liberación latinoamericana no ha dicho todavía su última palabra. El pontificado de Francisco ha abierto de nuevo las puertas para una nueva primavera teológica del continente desde una opción preferencial por los pobres. 


\section{LISTA DE REFERENCIAS}

Martínez Andrade, Luis. (2015). Las dudas de Dios. Teología de la liberación, ecología y movimientos sociales. Santander: Otramérica.

Bloch, Ernst. (2007). El principio esperanza. (Felipe González Vicén, Trad.). Madrid: Trotta.

Boff, Clodovis. (1990). "Epistemología y método de la teología de la liberación”. En Ignacio Ellacuría y Jon Sobrino. Mysterium Liberationis, Conceptos fundamentales de la Teología de la Liberación, Tomo I. (79-114). Madrid: Trotta.

Casaldáliga, Pedro y Vigil, José María. (1992). Espiritualidad de la liberación. Santander: Sal Terrae.

Holloway, John. (2005). Change the World Without Taking Power, The Meaning of Revolution Today. Londres: Pluto Press.

Martínez Andrade, Luis. (2016). Écologie et Libération, Critique de la modernité dans la théologie de la libération. París: Van Dieren.

Metz, Johan Baptist. (2002). Dios y tiempo, Nueva teología política. Madrid: Trotta.

Schelling, F.W.J. (2002). Las edades del mundo, Textos de 1811 a 1815. (Jorge Navarro Pérez, Trad.). Madrid: Akal. 